\title{
Artificial neural networks and physical modeling for determination of baseline consumption of CHP plants
}

\author{
Francesco Rossi $^{\mathrm{a}, *}$, David Velázquez ${ }^{\mathrm{a}}$, Iñigo Monedero ${ }^{\mathrm{b}}$, Félix Biscarri ${ }^{\mathrm{b}}$ \\ a Department of Energy Engineering, Universidad de Sevilla, Spain \\ ${ }^{\mathrm{b}}$ Electronic Technology Department, Universidad de Sevilla, Spain
}

Keywords:

Baseline energy consumption

Industry

Cogeneration

ANN modeling

Thermodynamic modeling

\begin{abstract}
A B S T R A C T
An effective modeling technique is proposed for determining baseline energy consumption in the industry. A CHP plant is considered in the study that was subjected to a retrofit, which consisted of the implementation of some energy-saving measures. This study aims to recreate the post-retrofit energy consumption and production of the system in case it would be operating in its past configuration (before retrofit) i.e., the current consumption and production in the event that no energy-saving measures had been implemented. Two different modeling methodologies are applied to the CHP plant: thermodynamic modeling and artificial neural networks (ANN). Satisfactory results are obtained with both modeling techniques. Acceptable accuracy levels of prediction are detected, confirming good capability of the models for predicting plant behavior and their suitability for baseline energy consumption determining purposes. High level of robustness is observed for ANN against uncertainty affecting measured values of variables used as input in the models. The study demonstrates ANN great potential for assessing baseline consumption in energyintensive industry. Application of ANN technique would also help to overcome the limited availability of on-shelf thermodynamic software for modeling all specific typologies of existing industrial processes.
\end{abstract}

\section{Introduction}

The industry represents about 20\% of the European Union (EU)'s primary energy consumption. Although $30 \%$ improvement in energy intensity has been achieved in this sector during the last two decades, relevant potential remains for energy efficiency enhancement (Energy Efficiency Plan, 2011).

The European Commission is developing systematic plans aimed at rational energy use, like regular and mandatory energy audits in large industrial sites and incentives that EU member countries should establish for companies to implement energy management systems. Intensification of high-efficiency cogeneration plants is also included as an effective potential contributor to the energy efficiency of European industry.

In this scenario, energy studies acquire a decisive role in the competitiveness of the industrial sector, the main objective of energy audits being the identification of measures aimed at increasing equipment efficiency and reduction of energy consumption. Once the saving measures proposed in the energy audit have been implemented, an issue of relevant importance is the assessment of real benefits generated by the changes. Although it is to be hoped

\footnotetext{
* Corresponding author. Tel.: +34 647004965.

E-mail addresses: fraros@alum.us.es, fscorossi@hotmail.it (F. Rossi).
}

that the actual effects are not too different from the anticipated savings, a significant margin of error exists due to, among other factors, the reference conditions which the study was based on and the variability of those conditions in the real operation of the production process. The new consumption of the factory after the retrofit can be easily obtained, provided that adequate measuring instruments are installed and functioning properly. The energy saving achieved, on the contrary, cannot be measured, since this would suppose being able to measure the current consumption of industry in its past configuration (before retrofit). For these reasons, the impact of programs and projects for improving energy efficiency in the industry can only be estimated, as the difference between the current energy consumption (directly measurable) and consumption that would occur in the same period in the event that no saving measures had been implanted. This second term is often called by the name of baseline energy consumption.

The International Performance Measurement and Verification Protocol (Efficiency Valuation Organization (EVO), IPMVP Volume 1,2012 ) can be considered as the international reference text on measurement and verification $(\mathrm{M} \& \mathrm{~V})$ of energy savings from projects aimed at improving energy efficiency and reducing energy costs. One of the aspects highlighted in the protocol is that a key factor in the planning phase of a program of $M \& V$ of savings is the selection of the method that aims to solve the problem of 
determining the baseline consumption. The need for a clear formalization of the baseline development process is also stressed in the interesting work of (Reichl \& Kollmann, 2011). Among the various approaches proposed for determining the baseline consumption (U.S. EPA State Clean Energy, 2009), the most easily applicable is the engineering method, based on the use of standard formulas and assumptions for calculating the energy use before retrofit. However, the simplicity and practicality guaranteed by its implementation involves an associated level of uncertainty (Kelly Kissock \& Eger, 2008) that makes it unsuitable for systematic use in the industrial field. Statistical analyses are also contemplated, but this general term is actually used to refer to models of limited complexity aimed at determining "before" and "after" consumption taking into consideration few factors like changes in weather, facility occupancy and factory operating hours. Other suggested methods contemplate computer simulation for determining system energy performance. Finally, integrative methods can be used, combining some of the aforementioned approaches.

As evidenced by the literature survey (discussed below), no relevant applications of ANN modeling technique were detected for the determination of the energy consumption baseline in CHP systems, intended as the consumption of the system before the implementation of the efficiency enhancement measures. The objective of this paper is to present a valid modeling technique allowing an answer to the problem of determining the baseline energy consumption in the industry. The ANN approach is proposed, as an effective way of recognizing complex non-lineal patterns governing energy consumption in industrial production sites. Achievable levels of accuracy and suitability of ANNs in predicting the behavior of the system are also discussed, by comparing the ANN approach with the thoroughly tested thermodynamic modeling technique. A combined heat and power (CHP) plant is considered for the application of the proposed methodology. The extensive historical operating dataset available from the existing monitoring system is used to generate and validate both ANN and thermodynamic models. Cogeneration plants are often present in industrial sites and represent an efficient solution for electricity and heat supply to energy-intensive processes. According to the objective of this work, a CHP system can also be considered as an independent industrial unit, products of which are electricity and heat, e.g., in the form of steam delivered to the productive process.

Below is a brief summary of the literature consulted, stating some of the latest applications of ANN modeling to industrial and cogeneration plants.

Simplified methodologies have been proposed for determining baseline consumption and for verification of energy savings in the industry, based on lineal regression and multi-regression analysis (Dalgleish \& Grobler, 2003; Kelly Kissock \& Eger, 2008). Other more developed methods have been applied, like lineal combinations of influence variables and subsequent regression modeling for generating the baseline efficiency in industrial refining sites (Velázquez et al., 2013).

The ANN modeling approach is not a novelty in the industry, as evidenced by the applications for optimization of distillation processes and control of wastewater treatment units (Liau, Yang, \& Tsai, 2004; Mingzhi, Yongwen, Jinquan, \& Yan, 2009; Motlaghi, Jalali, \& Nili Ahmadabadi, 2008). Olanrewaju and Jimoh (2014) propose a hybrid approach based on Index Decomposition Analysis (IDA), ANN modeling and Data Envelopment Analysis (DEA), to predict the expected energy consumption in the industry and subsequently optimize the present energy use with reference to the predicted values. Monedero et al. (2012) apply ANN approach to model the best past operation of a petrochemical site, for comparison with present operation and efficiency optimizations purposes. ANN modeling has been frequently proposed also for cogenerations, combined cycles and power plants, with multiple objectives:
- Power prediction of the plant (Smrekar, Pandit, Fast, Assadi, \& De, 2010).

- Prediction and monitoring of thermal efficiency and pollutant emissions of the plant (Fantozzi \& Desideri, 1998; Flynn, Ritchie, \& Cregan, 2005; Lu \& Hogg, 2000; Pan, Flynn, \& Cregan, 2007; Tronci, Baratti, \& Servida, 2002).

- Adjustment of power generation to demand profile of the industry (Moghavvemi, Yang, \& Kashem, 1998).

- Reproducing the behavior of plant components (boilers, steam turbines, and superheaters) (Bekat, Erdogan, Inal, \& Genc, 2012; De, Kaiadi, Fast, \& Assadi, 2007; Du et al., 2011; Jia \& Xu, 2010; Ma, Wang, \& Ma, 2008; Olausson, Häggståhl, Arriagada, Dahlquist, \& Assadi, 2003).

- Optimization of load distribution and load disconnection for stability purposes in the case of fault of the system (Hsu, Chuang, \& Chen, 2011; Romero \& Shan, 2005).

- Optimization of operating parameters for plant efficiency maximization, in some cases through combined implementation of ANN and other optimization techniques, e.g., genetic algorithm (Arslan, 2011; Hajabdollahi, Hajabdollahi, \& Hajabdollahi, 2012; Rashidi, Galanis, Nazari, Basiri Parsa, \& Shamekhi, 2011; Suresh, Reddy, \& Kolar, 2011).

The main power generation unit of the CHP plant considered in this study is constituted by a gas turbine. Many examples exist in the literature of the ANN modeling approach applied to gas turbines, for condition monitoring and performance estimation (Asgari, Chen, Menhaj, \& Sainudiin, 2013; Barad, Ramaiahb, Giridhara, \& Krishnaiahb, 2012; Fast, Assadi, \& De, 2009a; Fast, Palmé, \& Genrup, 2009b; Lazzaretto \& Toffolo, 2001; Nikpey, Assadi, Breuhaus, \& Mørkved, 2014; Palmé, Breuhaus, Assadi, Klein, \& Kim, 2011), fault detection (Kong, Ki, Kang, \& Kho, 2004; Kong, Park, \& Kim, 2008; Simani \& Fantuzzi, 2000; Volponi, DePold, Ganguli, \& Daguang, 2003), control enhancement (Sisworahardjo, El-Sharkh, \& Alamb, 2008), and turbine diagnostics (Bettocchi, Pinelli, Spina, Venturini, \& Burgio, 2004).

Other examples of ANN methodology applied to industry for online monitoring, performance estimation and diagnostic purposes are represented by modeling of boilers (Arriagada, Costantini, Olausson, Assadi, \& Torisson, 2003; Chong, Wilcox, \& Ward, 2000; Chu et al., 2003; Hao, Kefa, \& Jianbo, 2001; Rusinowski \& Stanek, 2007; Teruel, Cortes, Diez, \& Arauzo, 2005), furnaces (Calisto, Martins, \& Afgan, 2008), circulating fluidized bed boilers (Liukkonen et al., 2011), compressors (Ghorbanian \& Gholamrezaei, 2009), refrigerating and heating systems (Kizilkan, 2011; Esen and Inalli; 2009), and fluidized bed dryers (Chen, Tsutsumi, Lin, \& Otawara, 2005; Satish \& Setty, 2005).

Other industrial applications of ANN involve more specific areas such as control of nuclear power plants (Oliveira \& Soares de Almeida, 2013), performance prediction of internal combustion engines (Canakci, Ozsezen, Arcaklioglu, \& Erdil, 2009; Oğuz, Saritas, \& Baydan, 2010; Tasdemir, Saritas, Ciniviz, \& Allahverdi, 2011; Yap \& Karri, 2013), modeling and control of fuel cells (Chávez-Ramírez et al., 2010; Hatti \& Tioursi, 2009), performance prediction and optimization of solar systems (Kalogirou, 2004; Sözen \& Akçayol, 2004), power output forecasting of wind power plants (Yeh, Yeh, Chang, Ke, \& Chung, 2014), control of hybrid wind-diesel power generators (Vargas-Martínez, Minchala Avila, Zhang, Garza-Castañón, \& Calle Ortiz, 2013), and prediction performance of photovoltaic panels (Karamirad, Omid, Alimardani, Mousazadeh, \& Navid Heidari, 2013).

\section{Description of CHP plant, implemented energy-saving measures and preliminary data processing}

The system at issue is a CHP plant at the service of a refining site. Fig. 1 shows a simplified schematic of the plant. The main components of the unit can be appreciated: 


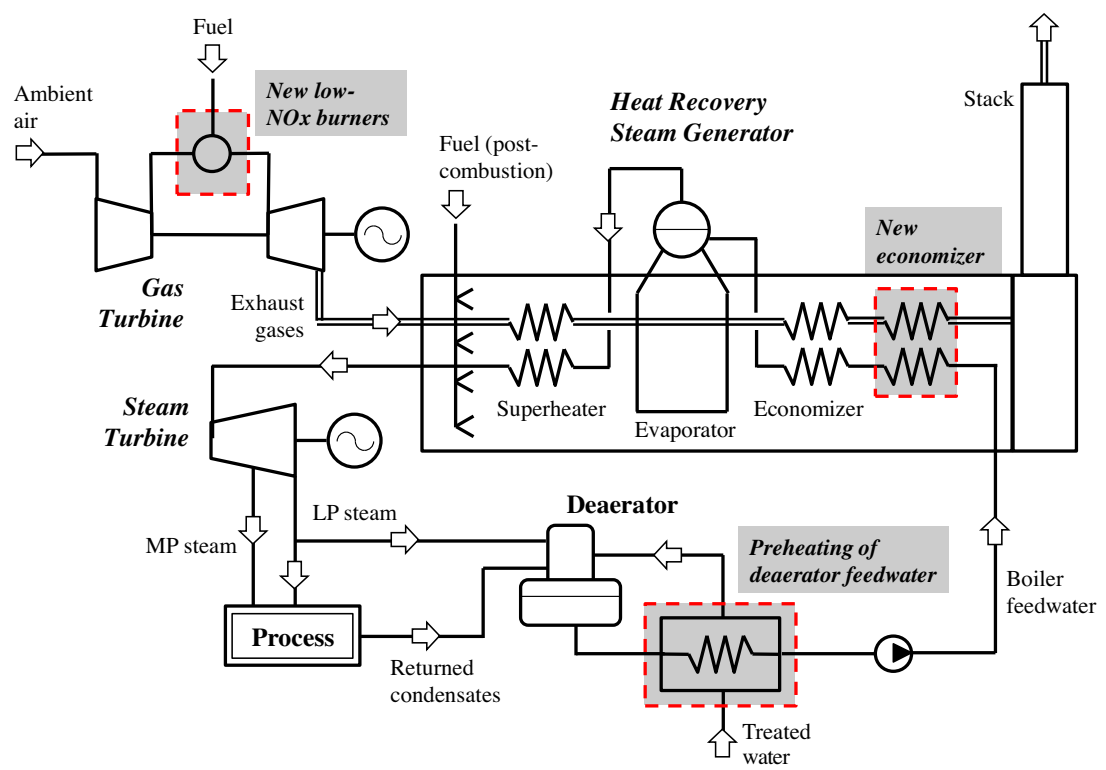

Fig. 1. Simplified diagram of the CHP plant and areas subject to energy-saving measures.

- Gas turbine (GT). Generates electricity from fuel burned in the combustion chamber, both for refinery use and for export to the grid of the production which exceeds demand.

- Heat recovery steam generator (HRSG). Equipment constituted by heat exchangers the function of which is to recover the heat contained in the flue gases at the outlet of the GT and contemporary steam generation. Post-combustion is also used to increase steam generation and meet the thermal demand of the refinery.

- Steam turbine (ST). Used for additional generation of electricity from steam generated in the HRSG. Part of the steam is extracted from the turbine before it completes its expansion, to be supplied to refinery at the proper pressure level required by the process. The remaining steam completes the expansion in the turbine to be delivered to the process at a lower pressure level.

From April to November 2008 a number of energy-saving projects were implemented in the CHP unit, by which the economic benefit of the plant was increased significantly. Fig. 1 evidences areas of implementation of projects, which were:

- Replacement of existing burners with Low- $\mathrm{NO}_{\mathrm{x}}$ burners in the GT combustion chamber. It allowed the cessation of steam injection into the combustion chamber, performed until meeting the emission levels required by legislation.

- Preheating of deaerator feed water and installation of a new economizer in the HRSG. A new heat exchanger was installed that preheats the water fed to the deaerator, contemporarily cooling HRSG feed water. The first effect of this measure was the reduction of steam consumption in the deaerator. A new heat exchanger was also installed in the HRSG (new economizer), to compensate the lower HRSG feed water temperature. As a second effect of the project, exploitation was thus enhanced of the GT gases heat content and stack gas temperature was reduced from 190 to $130^{\circ} \mathrm{C}$.

The main effect of all implemented measures was a significant reduction in steam self-consumption of the plant, which explains the subsequent increase of CHP plant profit. Moreover, saving projects impacted on other consumptions and productions, which also contribute significantly to the operating profit of cogeneration. The parameters directly affected by the projects, for which the construction of the baseline is required, are:

- Electricity production and fuel (natural gas) consumption in the GT.

- Medium pressure (MP) steam injected into the GT.

- Low pressure (LP) steam consumed in the deaerator.

As mentioned above, two different modeling methodologies were applied to the CHP plant, i.e., thermodynamic modeling and ANN modeling. Prior to that, a filtering of the collected data was necessary so that a valid database could be obtained for development of both models. A comprehensive data collection was conducted for most of the process variables. Records were obtained from distributed control system (DCS), through specific software that allows downloading historical data in Excel format. Plant monitoring is very exhaustive, and hourly data were collected for 134 variables, comprised between 02-16-2007 18:00 and 05-072009 00:00. These variables include the main operating parameters of all the components of the plant:

- GT: electricity generation, GT regulation parameters (e.g. inlet guide vane opening angle), pressure drop in air filters, properties of fuel, inlet air, exhaust gases and injected steam.

- HRSG: conditions of fuel fed to post-combustion, properties of exhaust gases and water/steam in the economizer, evaporator and superheaters, blowdown rate and stack exhaust gas temperature.

- Deaerator: operating pressure, properties of fed steam and boiler feed water.

- ST: electricity generation, properties of inlet live steam, extraction steam and steam to condenser.

- Other components: properties of streams in the existing heat exchangers of the plant for boiler feed water preheating, steam de-superheating stations, etc.

Previous data treatment was performed and anomalous registers were eliminated, associated with measurement faults or informatics errors in the acquisition process. A valid database for the 
following modeling phase was subsequently selected. The effectiveness and the outcome of this selection process are strongly bound to the level of knowledge of the operation of the plant. A deep mastery of the philosophy of operation and control of the system is fundamental to the purpose, and it always derives not only from the prior knowledge of the system, but also from the observation of the same recorded data. A good understanding of the system is thus necessary, whatever the method of modeling elected.

\section{ANN modeling}

ANN is an adaptive non-linear statistical data modeling technique consisting of interconnected artificial neurons processing data in parallel. Exhaustive introductions to ANN modeling are provided in most of the above-referenced works. The multi-layer perceptron (MLP) network type was employed in this study, and the supervised learning process was used for adjustment of network parameters. Before the training, the dataset was randomized and divided into training and test data subsets. The training set is used for weight adjustment and the test set is used after the training to assess the performance i.e., prediction capability of ANN by comparing calculated and desired values for a set of unknown data.

\subsection{ANN setup and training}

A multi-layer feed-forward structure was chosen for the ANN. A specific ANN was generated for each output variable (GT electricity production, GT fuel consumption, MP and LP steam consumptions) and IBM SPSS Modeler 14.1.0 software package was used to setup and train the models. Input variables in the models were selected by the authors, based on the knowledge of system physics. Input used for GT electricity production and GT fuel consumption were the ambient conditions (temperature, atmospheric pressure and humidity), the density and the lower heating value of the fuel, $\mathrm{NO}_{\mathrm{x}}$ emissions and a counter representing the aging status of the GT. The same inputs were used for GT steam injection, except for fuel density, which has not a significant influence over it. The steam consumption of deaerator was modeled as a function of its operating pressure, the ambient temperature, the steam production of the HRSG and the hot condensate mass flow returned from the process for preheating of deaerator feed water.

For each of the generated ANN, the output layer is represented by one neuron, while the number of hidden layers and neurons is not fixed, being two the maximum number of hidden layers contemplated in the study. The final architecture of the network was determined by a trial-and-error process, in which different trainings were performed with varying numbers of hidden layers and neurons, until the network with best prediction accuracy was selected. A first set of trainings was performed, observing the behavior of one-layered ANN with increasing number of neurons from 1 to 15 , fixed as the maximum limit of neurons in the analysis. Further increase of ANN complexity was considered unnecessary; as observed by Calisto et al. (2008), an excessive number of neurons, rather than having beneficial effects, may facilitate the overtraining and reduce the generalization capability of the network. ANN structures presenting local maxima in prediction performance were selected and the effect was observed of introducing a second hidden layer. The number of neurons in the second layer was increased for each selected ANN, from one to the same number of neurons of the first hidden layer. As suggested by Kong and Goo (2011), hyperbolic tangent sigmoid function and identity function were used as transfer functions in the hidden and output layers respectively. Range fields of data were rescaled before training to have values between 0 and 1 , to match the range of the activation function of the first hidden layer. The common and well proven back-propagation algorithm proposed by Rumelhart, Hinton, and Williams (1986) was applied to train the ANN and update the weights associated with neurons. Data are processed in the forward direction at each iteration (epoch) and output values are generated in the output layer. The calculated error between the desired output and the model prediction subsequently propagates in the backward direction by means of Gradient Descent algorithm with Momentum, a computationally efficient technique that allows minimizing the error by updating the connection weights. This method, widely explained in Moghavvemi et al. (1998), contemplates the use of two coefficients referred to as learning rate $(\eta)$ and momentum rate $(m)$. Coefficient $\eta$ is used to control the intensity of the weights modification: fast learning is obtained with high $\eta$ values, but it may lead to instability problems. Momentum is used to correct the current weight variation with a term that reflects the impact of past weight change. The weight vector is updated using the formula

$w_{k+1}=w_{k}-\eta_{k} g_{k}+m \Delta w_{k}$

where $k$ refers to the number of epochs and $g$ is the gradient of the error function $E(w)$ with respect to the weights, in turn defined as

$$
E(w)=\sum_{r=1}^{N R} E^{(r)}(w)
$$

being

$$
E^{(r)}(w)=\frac{1}{2} \sum_{n=1}^{N}\left(t_{n}^{(r)}-p_{n}^{(r)}\right)^{2}
$$

where $N R$ is the number of records, $N$ is the number of network outputs, $t_{n}$ is the target output value for output $\mathrm{n}$ and $p_{n}$ is the corresponding prediction generated by the network. The initial value of $\eta$ was set to 0.4 and $m$ was fixed to 0.9 . As proposed by Liang-yu, Jian-qiang, and Bing-shu (2002) and Kong and Goo (2011), dynamic variation of learning rate was used to increase stability of training process. Variable adjustments were applied to learning rate factor depending on the error behavior: no correction was used for error decrease and strong reduction is applied for error increase $(0.5 \mathrm{fac}-$ tor of correction), to prevent network unsteady problems. The factor $\mathrm{m}$ was kept constant, except for the situations in which

$\eta_{k}\left|g_{k}\right| \leq m\left|\Delta w_{k}\right|$

In these cases $m$ value is set at

$m=0.9 \eta_{k} \frac{\left|g_{k}\right|}{\left|\Delta w_{k}\right|}$

This correction being necessary to make sure that the weight change takes place in the right direction for error decrease.

\subsection{Prediction capability of the model}

A total of 6405 records were used for the training of the network. Data were pre-randomized and subsequently grouped in two different sets: $70 \%$ of data were used for training and the remaining $30 \%$ were used for testing at each epoch. The records of the training set were internally divided into a model building set and an overfit prevention set, which is used to track errors during training in order to avoid overtraining of the network, i.e., to prevent the network from becoming overly "specialized" in recognizing the patterns which it was trained with, thereby losing its generalization capability. The percentages of training data employed for model building and overfit prevention were $85 \%$ and $15 \%$, respectively, corresponding to $59.5 \%$ and $10.5 \%$ of total records. The criteria selected for performance evaluation was the accuracy coefficient defined by the formula: 
Accuracy $=\frac{1}{N R} \sum_{r=1}^{N R}\left(1-\frac{\left|t_{r}-p_{r}\right|}{\max _{i}\left(t_{i}\right)-\min _{i}\left(t_{i}\right)}\right)$

where $N R$ is the number of records, $t_{r}$ is the target output value of record $r$ and $p_{r}$ is the corresponding prediction generated by the network. The terms $\max \left(t_{i}\right)$ and $\min \left(t_{i}\right)$ in the denominator refer to the maximum and minimum values among all the targets, and subscript i was used to indicate that they do not vary with the index $r$. Mean absolute error (MAE), root mean square error (RMSE), and coefficient of determination $R^{2}$ (square of the Pearson product moment correlation coefficient $R$ ) were also calculated, to complete prediction capability analysis of the generated models:

$\mathrm{MAE}=\frac{1}{N R} \sum_{r=1}^{N R}\left|\frac{t_{r}-p_{r}}{t_{r}}\right|$

$\mathrm{RMSE}=\sqrt{\frac{1}{N R} \sum_{r=1}^{N R}\left(\frac{t_{r}-p_{r}}{t_{r}}\right)^{2}}$

$R=\frac{\sum_{r=1}^{N R}\left(t_{r}-\bar{t}\right)\left(p_{r}-\bar{p}\right)}{\sqrt{\sum_{r=1}^{N R}\left(t_{r}-\bar{t}\right)^{2}} \cdot \sqrt{\sum_{r=1}^{N R}\left(p_{r}-\bar{p}\right)^{2}}}$

Table 1 summarizes the accuracy levels achieved for GT electric power in the selection process of the final structure of the ANN model. Limited obtained variations of predictive capability confirm the slight influence of hidden neurons number on ANN performance observed by Bettocchi, Pinelli, Spina, and Venturini (2007) when data are affected by measurement errors. Local maxima can be observed for 3, 6 and 8 neurons in the first hidden layer. Maximum accuracy is calculated for 8 neurons and no further improvements are obtained augmenting neurons number. For that reason 3, 6 and 8-layer structures are selected for checking the effect of introducing a second hidden layer. As it may be observed, second hidden layer has no benefit for the case of 3 neurons, whereas slight improvements can be observed for any two-layer structures containing 6 and 8 neurons in the first hidden layer. The final configuration selected for ANN contains 8 neurons in the first layer and 3 neurons in the second, although the accuracy enhancement achieved with the second layer introduction is not relevant.
Fig. 2 shows obtained results for all generated ANN models. As it can be observed, the initial date of the modeling period does not coincide with the aforementioned one. Indeed the elimination of registers corresponding to the first months of operation was required, due to a prolonged faulty measurement of $\mathrm{NO}_{\mathrm{x}}$. The final dataset was so reduced to data comprised between 06-12-2007 07:00 and 04-21-2008 17:00 (6405 data). The first column of Fig. 2 contains the simultaneous plots of ANN predictions and measured registers, along with corresponding errors for each data point. The same information is presented in the second column, in the form of cross plots of predicted values against measured values. Good agreement between predicted and actual values can be observed from the first column, and correct random (and not systematic) behavior of deviations from the diagonal in the second column. A strong smoothening tendency is observed in the deaerator steam consumption for high steam flow rates (bottom left graph of Fig. 2). This is mainly due to the low number of available data for training the model in that period, which does not reflect the normal operation of the plant. The plant in its original pre-retrofit configuration includes a heat exchanger for preheating of deaerator feed water with hot condensates returned from the process. During the period at issue the heat exchanger was not receiving condensates, thus augmenting the steam consumption in the deaerator. Apart from these aspects, the relative errors calculated in that zone are still acceptable and comparable with those obtained in the rest of the modeled period.

Additional graphs are also presented in Fig. 3, showing the same results of Fig. 2 but for a smaller period of time (two weeks). This may be useful to observe the graphical correspondence between the values of accuracy and $R^{2}$ achieved and the capacity of the models to reproduce the registered profiles, in terms of flexibility and ability to follow the tendencies and fluctuations of measured data.

With reference to Table 2, satisfactory values of all calculated performance parameters may be observed in GT electricity production, demonstrating high model capability in predicting the outputs. Almost $89 \%$ of the points present errors lower than $1.0 \%$ and only $0.9 \%$ are higher than $2 \%$. Lower accuracy was obtained from GT fuel consumption. The tendency of the model to smoothen fluctuations of registered data may be observed in the generated plots and is also reflected by the low value of $R^{2}$. The strong influence of input data quality over model performance has to be considered in this specific case. Indeed the fluctuations of registered

Table 1

Selection of ANN structure for modeling of GT electricity production. Obtained prediction accuracies.

\begin{tabular}{|c|c|c|c|c|c|c|c|c|c|c|c|c|c|c|c|}
\hline \multicolumn{16}{|c|}{ One-layer feed-forward structure } \\
\hline $\begin{array}{l}\text { No. of neurons in the first } \\
\text { hidden layer }\end{array}$ & 1 & 2 & 3 & 4 & 5 & 6 & 7 & 8 & 9 & 10 & 11 & 12 & 13 & 14 & 15 \\
\hline Obtained accuracy $(\%)$ & 94,557 & 94,715 & 95,400 & 95,070 & 94,912 & 95,330 & 94,880 & $\mathbf{9 5 , 8 3 7}$ & 95,150 & 95,663 & 95,523 & 95,524 & 95,605 & 95,722 & 95,620 \\
\hline \multicolumn{16}{|c|}{ Two-layer feed-forward structure } \\
\hline $\begin{array}{l}\text { No. of neurons in the first- } \\
\text { second hidden layer }\end{array}$ & $3-1$ & $3-2$ & $3-3$ & & & & & & & & & & & & \\
\hline Obtained accuracy (\%) & 94,768 & 95,399 & 95,341 & & & & & & & & & & & & \\
\hline $\begin{array}{l}\text { No. of neurons in the first- } \\
\text { second hidden layer }\end{array}$ & $6-1$ & $6-2$ & $6-3$ & $6-4$ & $6-5$ & $6-6$ & & & & & & & & & \\
\hline Obtained accuracy (\%) & 95,150 & 95,268 & 95,493 & 95,393 & 95,495 & 95,485 & & & & & & & & & \\
\hline $\begin{array}{l}\text { No. of neurons in the first- } \\
\text { second hidden layer }\end{array}$ & $8-1$ & $8-2$ & $8-3$ & $8-4$ & $8-5$ & $8-6$ & $8-7$ & $8-8$ & & & & & & & \\
\hline Obtained accuracy (\%) & 95,310 & 95,532 & 95,850 & 95,338 & 95,508 & 95,254 & 95,091 & 95,600 & & & & & & & \\
\hline
\end{tabular}



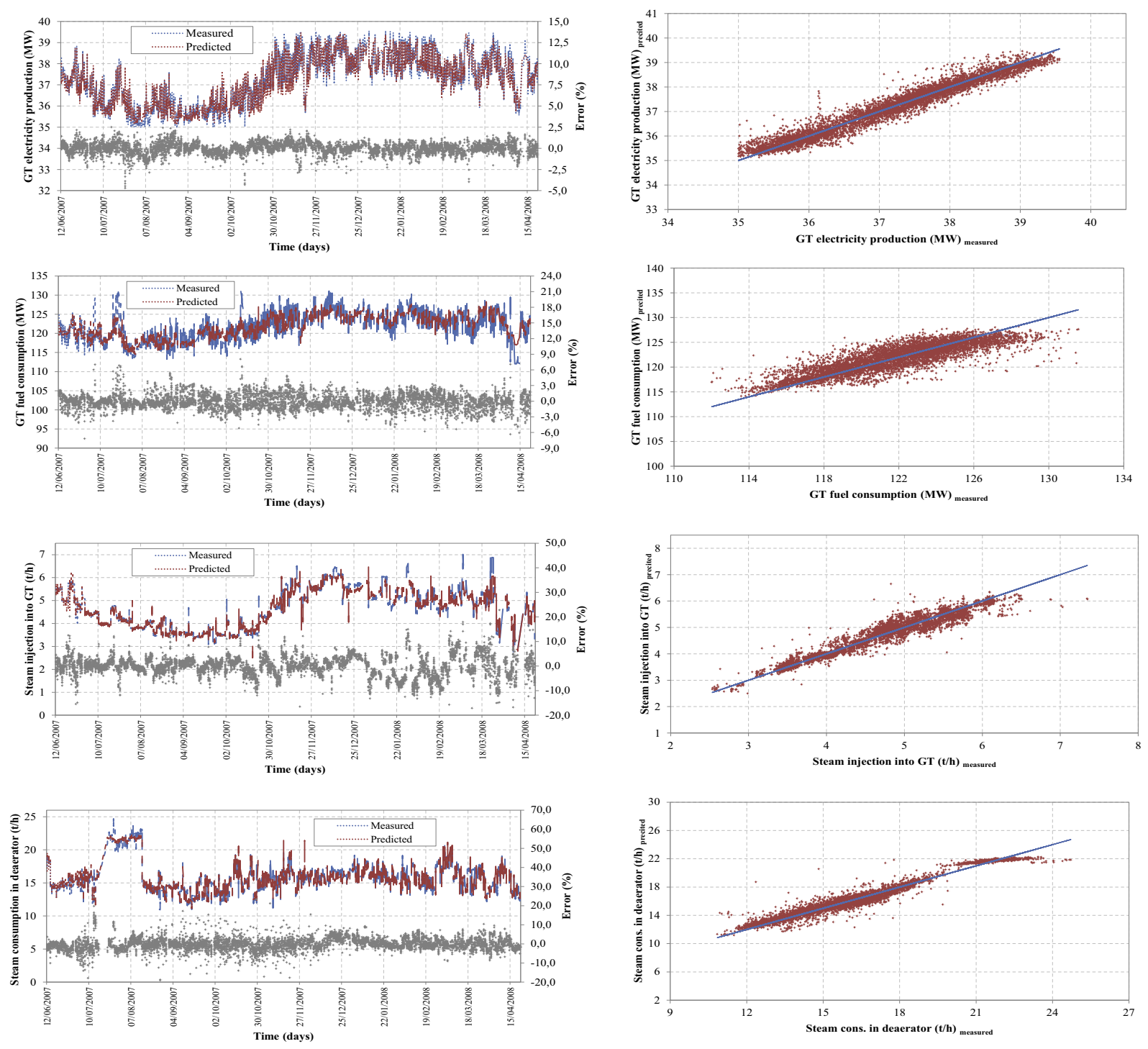

Fig. 2. ANN models. Predictions, measured registers and corresponding errors.

data are not representative of the real GT operation. They are mainly due to the different frequencies of data acquisition for the two parameters, product of which gives GT fuel consumption in MW: fuel mass flow rate and fuel heating value. The first is measured on an hourly basis and the latter proceeds from the daily laboratory analysis. Nevertheless model prediction capability is still acceptable, since almost $86 \%$ of the calculated errors are lower than $2.0 \%$ and only $0.4 \%$ are higher than $5 \%$. Models generated for GT steam injection and steam consumption of deaerator reproduce correctly tendencies of registered data, as confirmed by the calculated values of $R^{2}$ and accuracy. As it was expected, higher MAE and RMSE values were calculated for these two models, due to the relevant error level commonly associated with on-line measurement of steam flow rates. On average, $85 \%$ of errors are lower than $5.0 \%$ for these two modeled parameters.

Summarizing, obtained accuracy levels and errors allow asserting that the generated ANN models captured correctly the behavior of the CHP plant. The generalization capability is regarded as satisfactory for baseline energy consumption determining purposes, since the order of magnitude of the obtained errors is comparable with the uncertainty associated with measuring instruments.

\section{Thermodynamic modeling}

The same energy consumption and generation parameters were modeled using a thermodynamic simulator. The model was performed with Thermoflex (release 23.0), (Thermoflow Inc., 2013) a specific software for thermal systems modeling specially conceived for power generation and CHP plants.

\subsection{Model description}

The generated model reproduces the CHP plant configuration in the period prior to the implementation of saving projects. Fig. 4 shows the diagram of the model used for the simulation. As it can be observed, ST was not included in the model, due to the fact that the operation and electricity production of ST was not affected by energy saving measures. Indeed, the electricity generated by the ST is determined by the conditions (mass flow, temperature and pressure) of inlet live steam and the amount of steam extracted. The production and conditions of live steam entering the turbine are continuously controlled by means of the post-combustion fuel regulation system. It implies that the changes caused by saving 

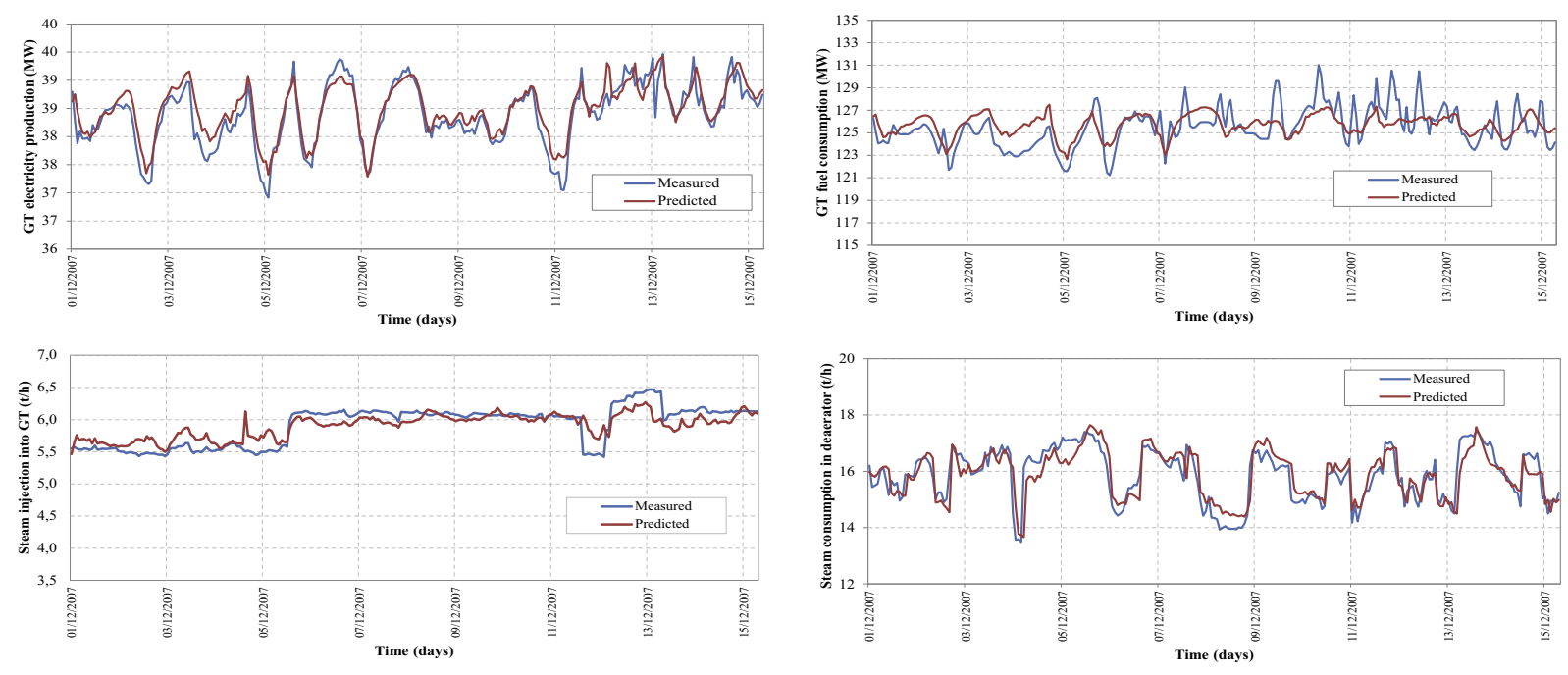

Fig. 3. ANN models. Predictions, measured registers and corresponding errors. Results for one month.

measures in the conditions of GT exhaust gases do not affect the conditions of the steam entering the ST. On the other hand, the percentage of steam extracted from the turbine only depends on the process demand of MP and LP steam. As previously commented, steam auto-consumptions of the plant decreased as a consequence of the implementation of the energy conservation measures. This caused an increase of MP and LP steam exported to the process. In case the process not having the capacity to absorb these changes, this would have led to modify the form of controlling steam extraction from the ST. Nevertheless, no excess of steam export was registered, since the exportation increase was compensated by load reduction of other auxiliary equipment supplying steam to the process. For these reasons, the operation of the ST did not suffer changes, thus confirming the independency between ST electricity generation and the energy saving measures.

The main components of the plant can be observed: GT, HRSG, heat exchangers train for preheating of treated water, and deaerator. The model reproduces the main plant control philosophy: a control loop was implemented for HRSG load, which allows assigning live steam flow produced as an input variable to the model. For model adjustment, the plant was simulated in off-design conditions and model outputs were compared with measured data, until satisfactory matching between data and measurements was obtained. The model tuning was performed manually, although Thermoflow special features would be available for carrying it out automatically. This way, a model was obtained capable of simulating GT partial load operation and reproducing the actuation of the real control system: GT load can be specified in the simulator both in the form of a specific GT electricity production and as a fixed percentage of GT nominal power. The software allowed endowing the model with the appropriate level of detail to reproduce the actual complexity of plant operation. For instance, the boiler feed water turbopump was included in the scheme, driven by MP steam proceeding from desuperheating section, as well as the flash tank for LP steam recovery from HRSG blowdown.

\subsection{Preliminary assumptions}

According to the plant operation protocol prior to the installation of the new Low- $\mathrm{NO}_{\mathrm{x}}$ burners, the steam flow rate injected into the GT was manually controlled to maintain fixed levels of $\mathrm{NO}_{\mathrm{x}}$ emissions in GT exhaust. Such control was hardly reproducible in the model, since the control of GT steam injection for reduction of $\mathrm{NO}_{\mathrm{x}}$ emissions is not directly implementable in the software. A fixed value of GT steam-to-fuel ratio was assumed for the post-retrofit period, equal to the average recorded value in the pre-retrofit period, thus reducing somewhat the precision of the model. In return, the first months of operation of the CHP plant were not discarded for the simulation, as it was necessary for the case of ANN modeling. Indeed $\mathrm{NO}_{\mathrm{x}}$ emissions were not used as an input in the model and there was no reason to discard the period of faulty $\mathrm{NO}_{\mathrm{x}}$ measurement. The adjustment of some parameters depending on operating hours was also necessary to complete the setup of the model, e.g., GT fouling parameters. Since time is not contemplated among the inputs of the thermodynamic model, the effects of aging had to be determined separately for all the input variables directly depending on number of operating hours. A simplification was adopted for those variables, and the same trends observed in the pre-retrofit period were assumed for the GT degradation factors and air pressure losses in GT air admission line.

\subsection{Validation and prediction capability of the model}

For GT full load operation, brief periods of operation were selected to validate the model's ability to simulate consecutive days of operation. The selection was carried out so that different scenarios of plant operation were covered, according to the main operating parameters of the plant: GT electricity production, fuel burned in post-combustion, steam injection in GT, etc. A total of $500 \mathrm{~h}$ of operation were simulated to validate the model at full load. For partial load operation all recorded data were used, due to their smaller amount: 280 measured data. For the validation, a tool was developed which allows performing massive simulations. An Excel spreadsheet was used to link to the simulation file that allowed automatically simulating a number of times set by the user. Thermoflex software provides Visual Basic (VBA) code for that purpose. Only few modifications had to be introduced to adapt it to the specific simulation model. Fig. 5 shows validation results for GT electricity production at full load. Data are presented sorted by date, so that performed selection can be observed, along with the strong influence of ambient temperature over the evolution of GT electrical output. For clarity, the simulated sections were unified and displayed adjacent in the second diagram. 


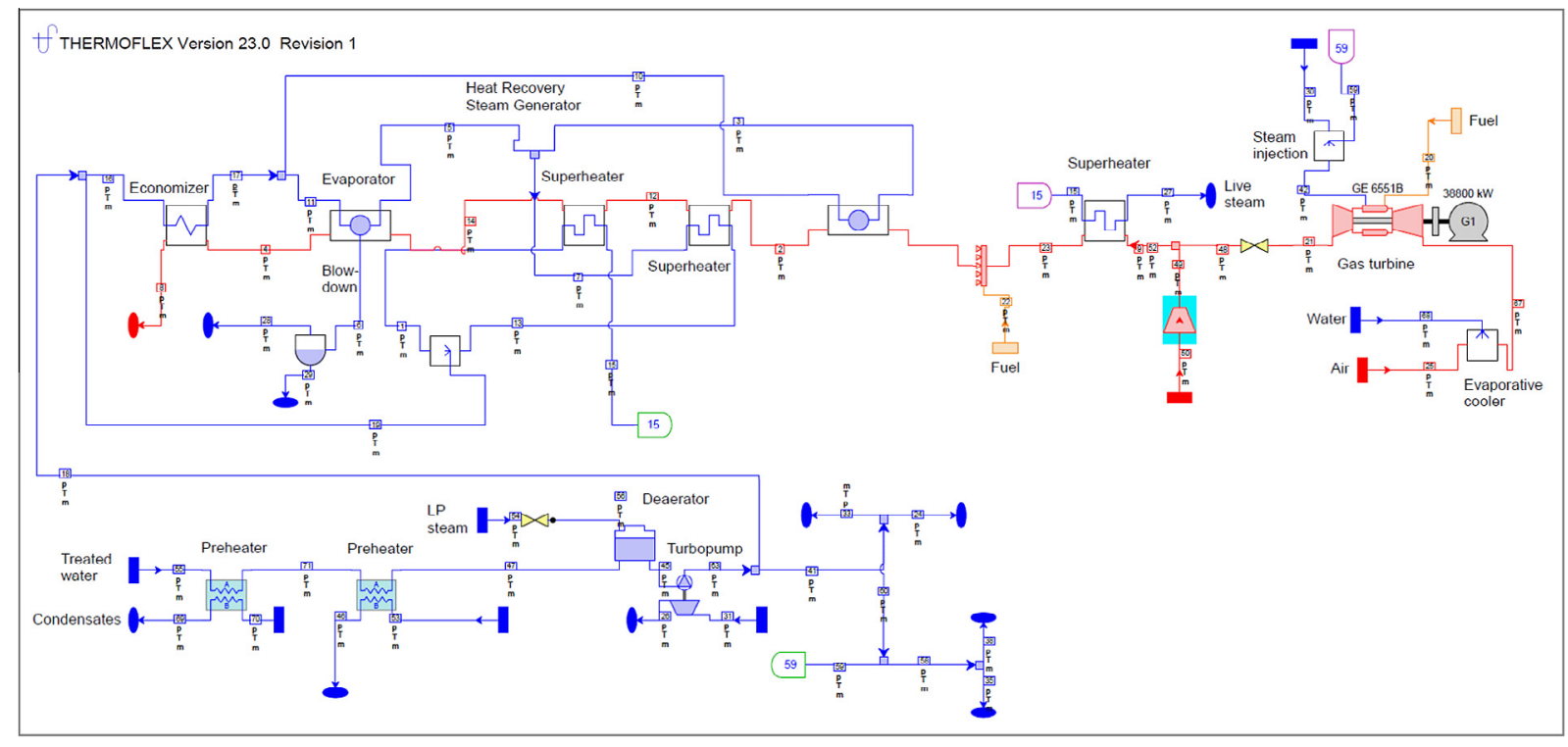

Fig. 4. Diagram of CHP simulation model (Thermoflex software).

Obtained error levels were relatively low, although sensibly higher than the corresponding ANN model. Only 57\% of the points presented errors lower than $1.0 \%$, compared to $89 \%$ of ANN predictions fulfilling the same condition. Nevertheless, the prediction capability of the model may be still considered satisfactory, as $83 \%$ of calculated errors were lower than $2 \%$ and only $0.1 \%$ higher than $5 \%$. No systematic error behavior was detected and the same random tendency was observed as for ANN models. For the sake of concision, results are not shown for the other modeled parameters. Such results confirmed the more than proven ability of the thermodynamic simulator to predict the behavior of this type of plants, although with somewhat less precision of ANN when it comes to reproducing a set of measured operating data. This can be mainly attributed to the high sensitivity of thermodynamic models to the quality of input data. The well-known data reconciliation (DR) technique would certainly help to correct the measurement errors, thus reducing its adverse effects on the model. For this purpose Thermoflow conceived a special DR software package, the application of which would contribute to enhance the model capacity of prediction.

\section{Results}

Fig. 6 shows the energy baselines obtained for the CHP plant, proceeding with the application of thermodynamic modeling technique. Results are indicated for the main consumption and production parameters of the plant, which were affected by the implementation of the previously described energy conservation measures:
- Replacement of existing burners with Low- $\mathrm{NO}_{\mathrm{x}}$ burners in the GT combustion chamber.

- Preheating of deaerator feed water and installation of a new economizer in the HRSG.

The baselines behave as expected. The baselines of electricity production and GT fuel consumption are higher than measurements. It is mainly due to the cessation of steam injection into the GT and the installation of a new stage of filtration in the GT air inlet line; a second filter had to be integrated in the system to prevent the acceleration of GT fouling, since the new Low- $\mathrm{NO}_{\mathrm{x}}$ burners imposed the cessation of "carbo-blasting" a cleaning method based on injection of solid natural media. Therefore, periodic load reductions can be observed for GT cleaning, which would take place if the new burners had not been installed, as well as a corresponding decrease in steam injection. In the case of ANN modeling it was thought inappropriate to model the cleaning operation mode, due to the small number of records available. This approach has no influence on the results, given the low number of operating hours in cleaning mode and considering the ultimate goal of the study, which is the determination of the economic benefit of implementing energy-saving measures. Among the obtained trends, exceptional crossings occur between measured data and energy baselines. For GT fuel baseline consumption, crossings may be observed during continuous intervals of operation. These isolated cases are likely to be attributed to measurement errors. Actually these values were removed for ANN modeling for being out of range. In Fig. 7 both energy baselines predicted by ANN
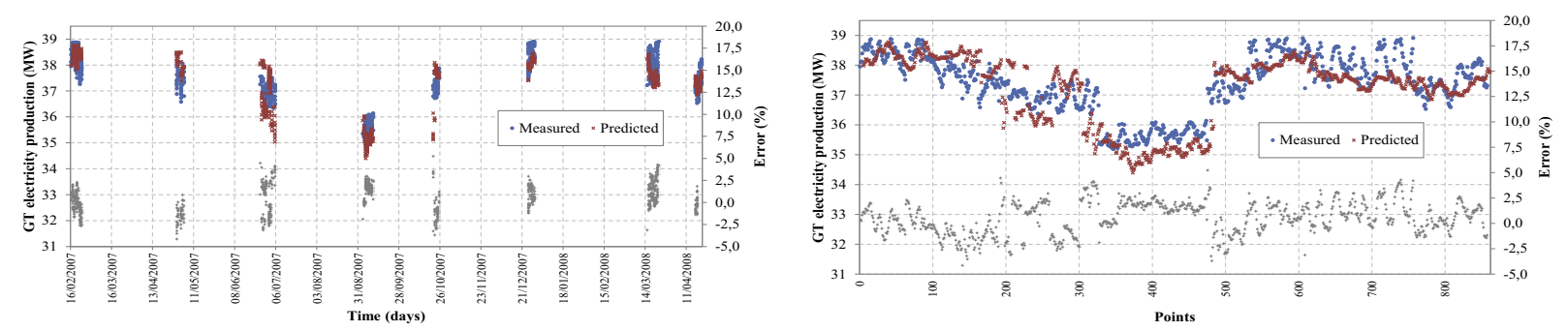

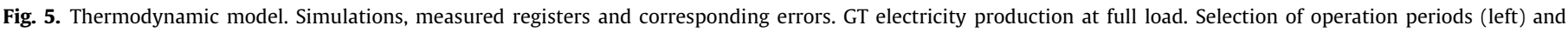
unification of selected periods (right). 

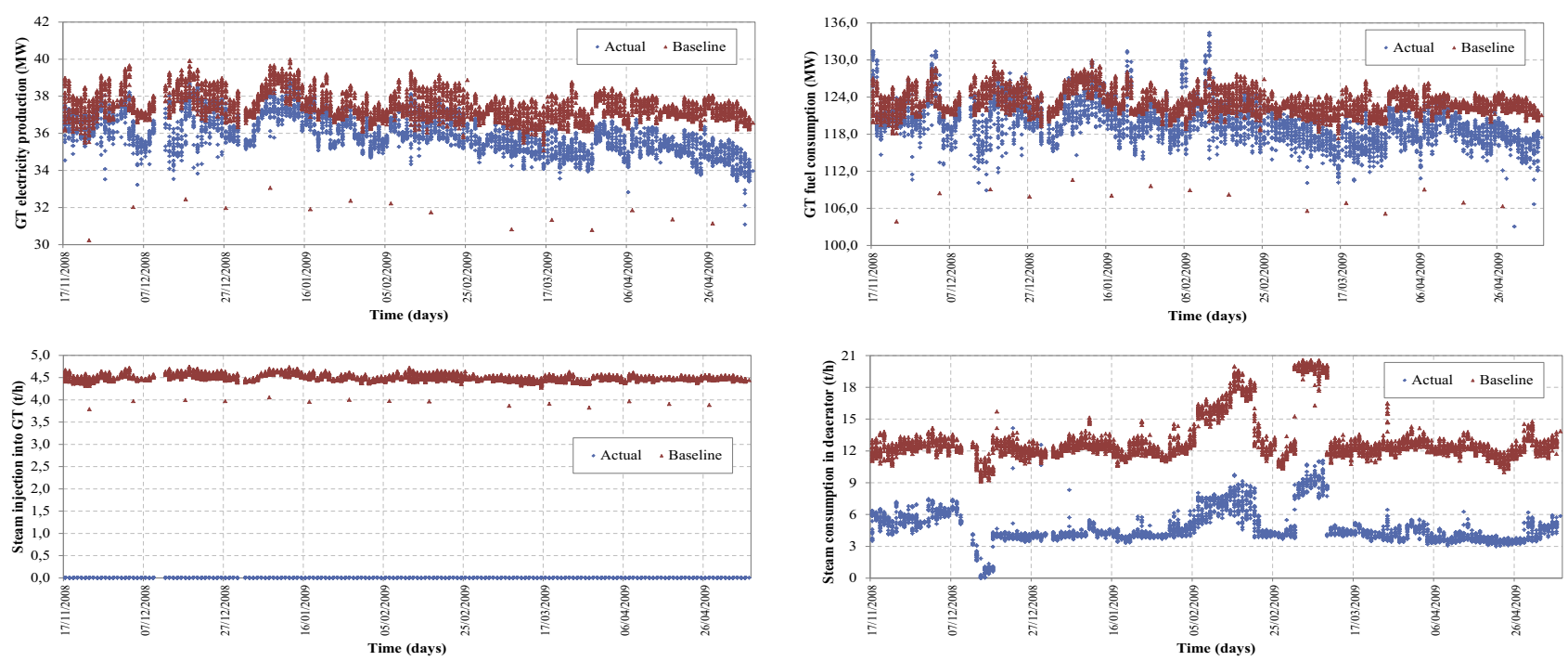

Fig. 6. Predicted and measured energy production and consumptions of CHP in the post-retrofit period.

and thermodynamic models are represented, together with the percentage differences between them.

The results for predicted GT electricity production and fuel consumption indicate relatively low differences between generated baselines, in the order of $3-5 \%$. Predictions obtained from ANN modeling for these two parameters show a tendency to exceed thermodynamic baseline in the second part of the observed period. A source of inaccuracy which the differences could be addressed to is the approximate approach that was adopted to reproduce GT aging in thermodynamic modeling. On the one hand, aging parameters were used as an adjustable input to better reproduce measured data when validating the thermodynamic model for pre retrofit period. On the other hand, those parameters generate an environment of uncertainty in the post retrofit period: the same trends were reproduced as for the pre retrofit period and there is no warranty that it corresponds to the real CHP operation. Another possible cause of the discrepancies could be associated with the fuel feed temperature, not contemplated in the ANN model. After the implementation of energy saving measures, fuel preheating was introduced as a practice in plant operation. This resulted in a slight reduction of GT fuel consumption and electricity production. Fuel temperature could not be included as an input to ANN models, since fuel was supplied to GT at ambient temperature in pre retrofit period and the slight fluctuations registered were not sufficient to appreciate its effects. More relevant differences between the models were detected for steam injected into the GT, the differences ranging up to $30-35 \%$. In this case better results were achieved with the ANN modeling approach. The discrepancies are mainly associated with the limitations of thermodynamic model when reproducing the real plant control for $\mathrm{NO}_{\mathrm{x}}$ emissions reduction, as discussed above. Concerning the effect of the second saving project (pre-heating of deaerator feed water), the differences are
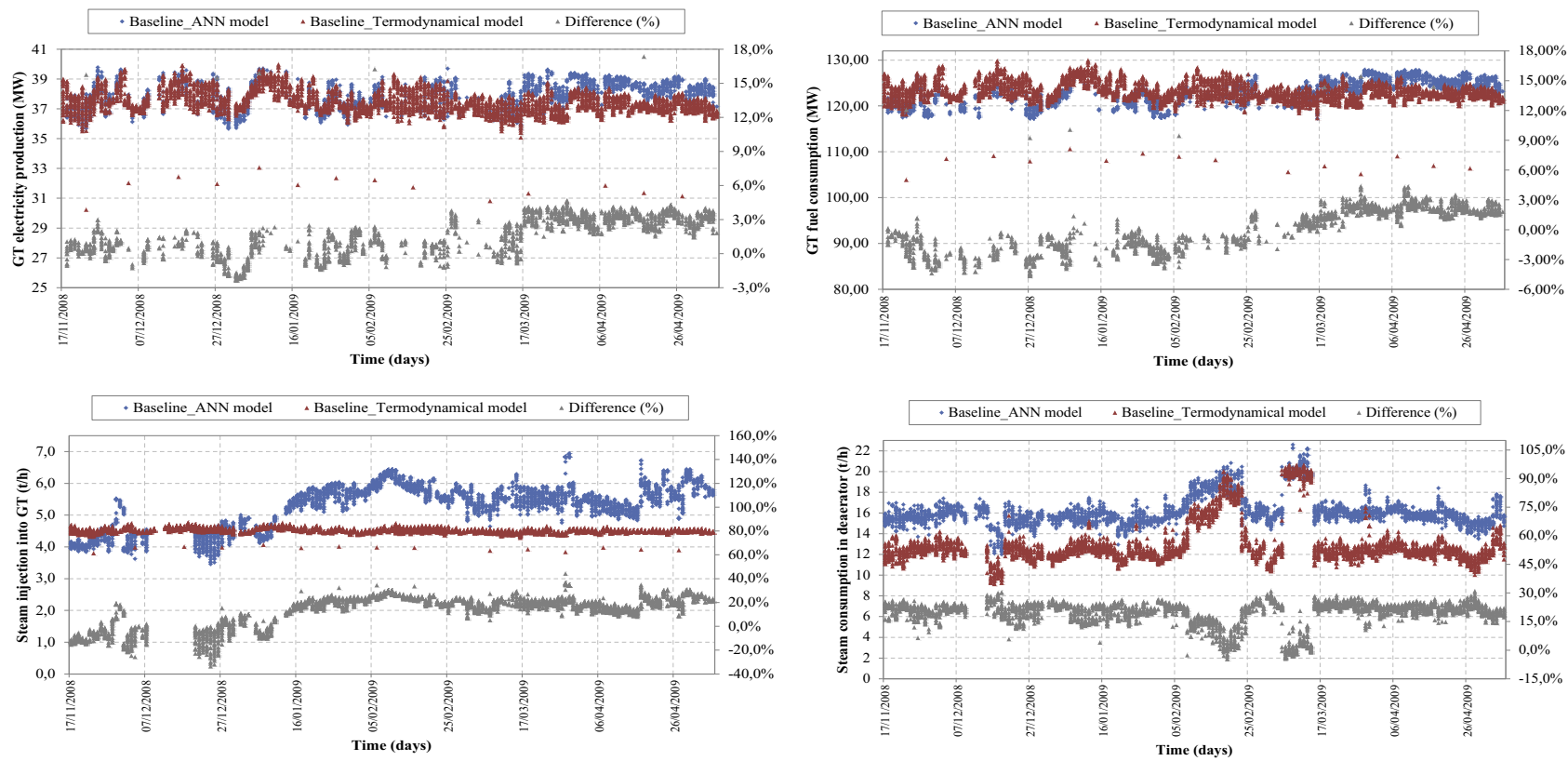

Fig. 7. Energy baselines obtained with ANN and thermodynamic modeling. 
Table 2

Final structure and prediction performance of the generated ANN models.

\begin{tabular}{|c|c|c|c|c|c|c|c|c|c|c|c|c|c|c|}
\hline \multirow{2}{*}{$\begin{array}{l}\text { Modeled } \\
\text { parameter }\end{array}$} & \multirow{2}{*}{$\begin{array}{l}\text { No. of } \\
\text { input } \\
\text { neurons }\end{array}$} & \multirow{2}{*}{$\begin{array}{l}\text { No. of neurons in } \\
\text { the first hidden } \\
\text { layer }\end{array}$} & \multirow{2}{*}{$\begin{array}{l}\text { No. of neurons in the } \\
\text { second hidden layer }\end{array}$} & \multicolumn{7}{|c|}{ No. of neurons in the second hidden layer } & \multirow{2}{*}{$\begin{array}{l}\text { MAE } \\
-(\%)\end{array}$} & \multirow{2}{*}{$\begin{array}{l}\text { RMSE } \\
(\%)\end{array}$} & \multirow{2}{*}{$R^{2}$} & \multirow{2}{*}{$\begin{array}{l}\text { Accuracy } \\
(\%)\end{array}$} \\
\hline & & & & $\begin{array}{l}\text { Below } \\
0.1 \%\end{array}$ & $0.1 \div 0.5 \%$ & $0.5 \div 1.0 \%$ & $1.0 \div 2.0 \%$ & $2.0 \div 5.0 \%$ & $5.0 \div 10.0 \%$ & $\begin{array}{l}\text { Above } \\
10.0 \%\end{array}$ & & & & \\
\hline $\begin{array}{l}\text { GT electricity } \\
\text { production }\end{array}$ & 7 & 8 & 3 & 13.5 & 45.8 & 29.3 & 10.5 & 0.9 & 0.0 & 0.0 & 0.51 & 0.67 & 0.95 & 95.85 \\
\hline $\begin{array}{l}\text { GT fuel } \\
\text { consumption }\end{array}$ & 7 & 7 & 2 & 6.6 & 24.5 & 26.0 & 28.4 & 14.1 & 0.4 & 0.0 & 1.08 & 1.41 & 0.74 & 493.29 \\
\hline $\begin{array}{l}\text { MP steam } \\
\text { injection into } \\
\text { GT }\end{array}$ & 6 & 12 & 5 & 2.2 & 9.7 & 11.2 & 20.8 & 35.9 & 17.4 & 2.8 & 3.16 & 4.32 & 0.94 & 496.90 \\
\hline $\begin{array}{l}\text { LP steam } \\
\text { consumed in } \\
\text { deaerator }\end{array}$ & 4 & 3 & 1 & 3.1 & 11.5 & 15.2 & 25.0 & 34.6 & 8.7 & 1.9 & 2.45 & 3.58 & 0.94 & 497.22 \\
\hline
\end{tabular}

relevant again: steam consumption in the deaerator predicted by thermodynamic simulation is significantly lower, due to the high measurement uncertainty of treated water flow, which induces error propagation in the simulation of the water preheating line. Hence, the differences are smaller for the hours of operation in which the implanted saving measure is not active, i.e., the new exchanger installed is out of service and LP steam consumption is higher. Discussed results reflect the main problem associated with energy baseline assessment, i.e., the great uncertainty environment and the absence of reference data for comparison characterizing the post-retrofit period. Limiting this uncertainty was indeed the main objective of this study, aimed at developing advanced and reliable modeling techniques for determination of credible baseline energy profiles. As regards the fidelity of the models, it is logical that it cannot be appreciated from the generated baselines, but prediction accuracy is to be rather detected during the validation process of the models. In this sense, the reader can refer to the previous sections of this paper discussing the validation results of both ANN and thermodynamic models.

\section{Conclusions}

Two different modeling approaches were used to determine the baseline of energy consumption and production in a CHP plant. ANN modeling and thermodynamic simulation were compared, both showing satisfactory levels of accuracy and suitability for baseline construction. The main potentials and inconveniences associated with each one of the analyzed methodologies were detected during the study.

Concerning ANN modeling, the potential versatility and utility of this technique was demonstrated. High accuracy was observed in the results, being the error levels obtained comparable with the uncertainty of measured data. The models showed satisfactory robustness against the errors contained in measured values of input variables. Another detached feature of ANN models is their practicality, which make them easily usable on different media like spreadsheets, programming, etc.

However, in the course of work, the main drawback associated with the ANN modeling arose, i.e., the vulnerability to changes in operating parameters outside the range for which the model was trained. A common feature to statistical models in general is the need for input data to contain fluctuations representative of system operation. ANNs do not guarantee accuracy outside the ranges for which they were generated and the effects cannot be reproduced of the variables for which no changes were recorded. Also, when records for output variables are erroneous, the error is insurmountable by ANN models since they were trained through these records. A clarification is also necessary, with respect to the simplicity of development and application of ANN models. Although the "black box" philosophy of ANN modeling technique might suggest the contrary, the presented analysis shows that ANN approach cannot elude a deep knowledge of the physics of the system. This is a factor of paramount importance, since the selected database inevitably affects the result of the ANN training. In the case of thermodynamic modeling the problem of system knowledge is rather related to the construction of the model, being the selection of data less critical. Indeed, deviations of thermodynamic simulations from measured registers can even be a valuable aid for the revision of the selected database.

Regarding thermodynamic modeling, obtained results as well as previous experience in the use of the simulator confirmed its remarkable ability to predict the behavior and performance of CHP plants with satisfactory level of accuracy. Also, thermodynamic modeling is not conditioned by the richness of historical data available, since it is not based on statistics. This can be a great advantage, given the problems involved in the acquisition of reliable measurements in almost any industrial plant.

On the other hand, the high sensitivity to measurement errors emerged for this modeling method: faulty meters impact adversely on the variables which are calculated from these measurements. This directly affects the simulation, which solves the mass and energy balances based on these inputs, contrary to what happens to ANN models. Some limitations were also detected when performing a complete modeling of the plant, and some simplifying assumptions had to be introduced, thus reducing the fidelity of reproduction of plant operation. It is the case of the steam flow injection into the GT, which cannot be directly predicted as a function of $\mathrm{NO}_{\mathrm{x}}$ emission levels. A second case is represented by the inability to include operating hours as input variables to the model. It makes necessary the adjustment of equipment aging parameters, which complicates the simulation if the aim is reproducing continuous time intervals of plant operation.

With respect to the times required for computation, during the validation phase the problem arose of long waiting times for the simulation of continuous periods of operation. However this is not a problem for the construction of the baseline, since its determination is performed periodically and response times of the simulator are more than acceptable for the intended purpose.

Some aspects are also worth noting related to the behavior of the models against uncertainty. The modeling of a system by thermodynamic simulation is based on the physical behavior of plant equipment. This is advantageous, since detection is possible of measurement errors and therefore the model, by means of its results, may provide more reliable values for those parameters with high uncertainties in their measurements. However, if these errors occur in the input variables, risk of propagation exists and adjustments or complementary calculations are necessary. ANN modeling may help to overcome this problem due to the "black box" treatment that it implies; when modeling variables with respect 
to others, the error is already included in the model, so that consistent results can be obtained starting from measurements that contain a certain error. Obviously this is only possible when it comes to errors within acceptable levels because the data quality is still a determining factor when making use of ANN modeling.

The application of the two proposed modeling methodologies yielded satisfactory results for the determination of baseline consumption in a CHP plant. The ANN models showed a special robustness against the error contained in measurements of input variables, which has been seen adversely affecting the proper development of thermodynamic simulation models. Nevertheless, DR technique would help to improve the quality of the input data in the model and would constitute a valid help to increase the predictive capacity of thermodynamic models. Owing to the limited market availability of specific modeling software to cover all the different typologies of industrial processes, more suitability is also expected in ANN employment for general industrial processes.

Apart from the work presented in this paper, more evidence is needed of the applicability of the methodology proposed, and its effectiveness should be proven for different industrial applications. ANNbased energy consumption models should be obtained for many other cases, identifying and addressing the main specific issues characterizing the big variety of production processes existing in the industry.

Moreover, a high potential exists for the utilization of ANN modeling technique for energy baseline determination, with other purposes than M\&V of savings. For instance, the application of ANN approach should be investigated for determining the reference consumption line in industrial sites, representing the normal operation of the facilities. The generated reference could be subsequently implemented in the consumption monitoring system of the plant, and would help to identify the deviations from the reference energy consumption and detect the main causes of those deviations (inefficient plant operation, faults of measuring instruments, etc.).

The need for proper establishment of energy baselines is clearly expressed also in the ISO 50001:2001 international standard for energy management systems. In this sense, the use of methods such as that proposed or other advanced methods for modeling of nonlinear systems should be taken into consideration, in substitution of the methods that are often adopted in the industrial facilities, based on simplifying assumptions which do not allow a rigorous determination of the energy baseline, thus reducing the effectiveness of the energy management system implemented.

\section{References}

Arriagada, J., Costantini, M., Olausson, P., Assadi, M., \& Torisson, T. (2003). Artificial neural network model for a biomass-fuelled boiler. Proceedings of the ASME Turbo Expo. Atlanta, Georgia, USA.

Arslan, O. (2011). Power generation from medium temperature geothermal resources: ANN-based optimization of Kalina cycle system-34. Energy, 36, 2528-2534.

Asgari, H., Chen, X. Q., Menhaj, M. B., \& Sainudiin, R. (2013). Artificial neural network-based system identification for a single-shaft gas turbine. Journal of Engineering for Gas Turbines and Power, 135(9).

Barad, S. G., Ramaiahb, P. V., Giridhara, R. K., \& Krishnaiahb, G. (2012). Neural network approach for a combined performance and mechanical health monitoring of a gas turbine engine. Mechanical Systems and Signal Processing, 27, 729-742.

Bekat, T., Erdogan, M., Inal, F., \& Genc, A. (2012). Prediction of the bottom ash formed in a coal-fired power plant using artificial neural networks. Energy, 45, $882-887$.

Bettocchi, R., Pinelli, M., Spina, P. R., Venturini, M., \& Burgio, M. (2004). Set up of a robust neural network for gas turbine simulation. ASME. Paper no. GT200453421.

Bettocchi, R., Pinelli, M., Spina, P. R., \& Venturini, M. (2007). Artificial intelligence for the diagnostics of gas turbines - part I: Neural network approach. Journal of Engineering for Gas Turbines and Power, 129, 711-719.

Calisto, H., Martins, N., \& Afgan, N. (2008). Diagnostic system for boilers and furnaces using CFD and neural networks. Expert Systems with Applications, 35, $1780-1787$.

Canakci, M., Ozsezen, A. N., Arcaklioglu, E., \& Erdil, A. (2009). Prediction of performance and exhaust emissions of a diesel engine fueled with biodiesel produced from waste frying palm oil. Expert Systems with Applications, 36 9268-9280.

Chávez-Ramírez, A. U., Muñoz-Guerrero, R., Durón-Torres, S. M., Ferraro, M., Brunaccini, G., Sergi, F., et al. (2010). High power fuel cell simulator based on artificial neural network. International Journal of Hydrogen Energy, 35, $12125-12133$.

Chen, W., Tsutsumi, A., Lin, H., \& Otawara, K. (2005). Modeling nonlinear dynamics of circulating fluidized beds using neural networks. China Particuology, 3, 84-89.

Chong, A. Z. S., Wilcox, S. J., Ward, J. (2000). Neural network models of the combustion derivatives emanating from a chain grate stoker fired boiler plant Proceedings of the IEEE seminar advanced sensors and instrumentation systems for combustion processes (pp. 6/1-6/4).

Chu, J. Z., Shieh, S. S., Jang, S. S., Chien, C. I., Wan, H. P., \& Ko, H. H. (2003). Constrained optimization of combustion in a simulated coal-fired boiler using artificial neural network model and information analysis. Fuel, 82, 693-703.

Dalgleish, A. Z., \& Grobler, L. J. (2003). Measurement and verification of a motor sequencing controller on a conveyor belt. Energy, 28, 913-927.

De, S., Kaiadi, M., Fast, M., \& Assadi, M. (2007). Development of an artificial neural network model for the steam process of a coal biomass co-fired combined heat and power (CHP) plant in Sweden. Energy, 32, 2099-2109.

Du, X., Liu, L., Xi, X., Yang, L., Yang, Y., Liu, Z., et al. (2011). Back pressure prediction of the direct air cooled power generating unit using the artificial neural network model. Applied Thermal Engineering, 31, 3009-3014.

Efficiency Valuation Organization (EVO). 2012. Concepts and options for determining energy and water savings. International performance measurement and verification protocol, Vol. 1.

Energy Efficiency Plan. (2011). European commission. Communication from the commission to the European parliament, the council, the European economic and social committee and the committee of the regions. Brussels.

Esen, H., \& Inalli, M. (2009). Modelling of a vertical ground coupled heat pump system by using artificial neural networks. Expert Systems with Applications, 36 10229-10238.

Fantozzi, F., \& Desideri, U. (1998). Simulation of power plant transients with artificial neural networks: application to an existing combined cycle. Proceedings of the Institution of Mechanical Engineers, Vol. 212, Part A, (pp. 299-313).

Fast, M., Assadi, M., \& De, S. (2009a). Development and multi-utility of an ANN model for an industrial gas turbine. Applied Energy, 86, 9-17.

Fast, M., Palmé, T., \& Genrup, M. (2009b). A novel approach for gas turbine condition monitoring combining cusum technique and artificial neural network. Proceedings of the ASME Turbo Expo 2009. Florida, USA.

Flynn, D., Ritchie, J., \& Cregan, M. (2005). Data mining techniques applied to power plant performance monitoring. Paper presented at IFAC world congress, Prague.

Ghorbanian, K., \& Gholamrezaei, M. (2009). An artificial neural network approach to compressor performance prediction. Applied Energy, 86, 1210-1221.

Hajabdollahi, F., Hajabdollahi, Z., \& Hajabdollahi, H. (2012). Soft computing based multi-objective optimization of steam cycle power plant using NSGA-II and ANN. Applied Soft Computing, 12, 3648-3655.

Hao, Z., Kefa, C., \& Jianbo, M. (2001). Combining neural network and genetic algorithms to optimize low $\mathrm{NO}_{\mathrm{x}}$ pulverized coal combustion. Fuel, 80, 2163-2169.

Hatti, M., \& Tioursi, M. (2009). Dynamic neural network controller model of PEM fuel cell system. International Journal of Hydrogen Energy, 34, 5015-5021.

Hsu, C.-T., Chuang, H.-J., \& Chen, C.-S. (2011). Adaptive load shedding for an industrial petroleum cogeneration system. Expert Systems with Applications, 38, 13967-13974.

Jia, R., \& Xu, H. (2010). ANN models for steam turbine power output toward condenser circulating water flux. Paper presented at the international conference on intelligent computation technology and automation, ICICTA 2010, Vol. 1, (pp. 719-721).

Kalogirou, S. A. (2004). Optimization of solar systems using artificial neuralnetworks and genetic algorithms. Applied Energy, 77, 383-405.

Karamirad, M., Omid, M., Alimardani, R., Mousazadeh, H., \& Navid Heidari, S. (2013). ANN based simulation and experimental verification of analytical four- and five-parameters models of PV modules. Simulation Modelling Practice and Theory, 34, 86-98.

Kelly Kissock, J., \& Eger, C. (2008). Measuring industrial energy savings. Applied Energy, 85, 347-361.

Kizilkan, Ö. (2011). Thermodynamic analysis of variable speed refrigeration system using artificial neural networks. Expert Systems with Applications, 38, 11686-11692.

Kong, C. D., \& Goo, Y. J. (2011). GUI type fault diagnostic program for a turboshaft engine using fuzzy and neural networks. International Journal of Turbo and JetEngines, 28, 31-39.

Kong, C. D., Ki, J. Y., Kang, M. C., \& Kho, S. H. (2004). Intelligent performance diagnostics of a gas turbine engine using user-friendly interface neural networks. Aircraft Engineering and Aerospace Technology. An International Journal, 76, 391-397.

Kong, C. D., Park, H. B., \& Kim, J. I. (2008). A Study on fault detection of a turboshaft engine using neural network method. KSAS International Journal, 15, 189-206.

Lazzaretto, A., \& Toffolo, A. (2001). Analytical and neural network models for gas turbine design and off-design simulation. International Journal of Applied Thermodynamics, 4, 173-182.

Liang-yu, M., Jian-qiang, G., \& Bing-shu, W. (2002). Fault intelligent diagnosis for high pressure feed water heater system of a $300 \mathrm{MW}$ coal-fired power unit 
based on improved BP neural network. IEEE Transactions on Neural Networks, 1535-1539.

Liau, L. C.-K., Yang, T. C.-K., \& Tsai, M.-T. (2004). Expert system of a crude oil distillation unit for process optimization using neural networks. Expert Systems with Applications, 26, 247-255.

Liukkonen, M., Heikkinen, M., Hiltunen, T., Hälikkä, E., Kuivalainen, R., \& Hiltunen, Y. (2011). Artificial neural networks for analysis of process states in fluidized bed combustion. Energy, 36, 339-347.

Lu, S., \& Hogg, B. W. (2000). Dynamic and nonlinear modelling of power plant by physical principles and neural networks. International Journal of Electrical Power E' Energy Systems, 22, 67-78.

Ma, J., Wang, B.-S., \& Ma, Y.-G. (2008). ANN-based real-time parameter optimization via GA for superheater model in power plant simulator. Proceedings of the 7th International Conference on Machine Learning and Cybernetics, ICMLC, Vol. 4, (pp. 2269-2273).

Mingzhi, H., Yongwen, M., Jinquan, W., \& Yan, W. (2009). Simulation of a paper mill wastewater treatment using a fuzzy neural network. Expert Systems with Applications, 36, 5064-5070.

Moghavvemi, M., Yang, S. S., \& Kashem, M. A. (1998). A practical neural network approach for power generation automation. Proceedings of Energy Management and Power Delivery. 1998 International Conference, Vol. 1, (pp. 305-310).

Monedero, I., Biscarri, F., León, C., Guerrero, J. I., González, R., \& Pérez-Lombard, L. (2012). Decision system based on neural networks to optimize the energy efficiency of a petrochemical plant. Expert Systems with Applications, 39, 9860-9867.

Motlaghi, S., Jalali, F., \& Nili Ahmadabadi, M. (2008). An expert system design for a crude oil distillation column with the neural networks model and the process optimization using genetic algorithm framework. Expert Systems with Applications, 35, 1540-1545.

Nikpey, H., Assadi, M., Breuhaus, P., \& Mørkved, P. T. (2014). Experimental evaluation and ANN modeling of a recuperative micro gas turbine burning mixtures of natural gas and biogas. Applied Energy, 117, 30-41.

Oğuz, H., Saritas, I., \& Baydan, H. E. (2010). Prediction of diesel engine performance using biofuels with artificial neural network. Expert Systems with Applications, 37, 6579-6586.

Olanrewaju, O. A., \& Jimoh, A. A. (2014). Review of energy models to the development of an efficient industrial energy model. Renewable and Sustainable Energy Reviews, 30, 661-671.

Olausson, P., Häggståhl, D., Arriagada, J., Dahlquist, E., \& Assadi, M. (2003). Hybrid model of an evaporative gas turbine power plant utilizing physical models and artificial neural network. Proceedings of the ASME Turbo Expo. Atlanta, Georgia, USA.

Oliveira, M. V., \& Soares de Almeida, J. C. (2013). Application of artificial intelligence techniques in modeling and control of a nuclear power plant pressurizer system. Progress in Nuclear Energy, 63, 71-85.

Palmé, T., Breuhaus, P., Assadi, M., Klein, A., \& Kim, M. (2011). New Alstom monitoring tools leveraging artificial neural network technologies. ASME Turbo Expo. Paper no. GT2011-45990.

Pan, L., Flynn, D., \& Cregan, M. (2007). Statistical model for power plants performance monitoring and analysis. Universities Power Engineering Conference, 2007. UPEC 2007, 121-126. 42nd International Conference.

Rashidi, M. M., Galanis, N., Nazari, F., Basiri Parsa, A., \& Shamekhi, L. (2011). Parametric analysis and optimization of regenerative Clausius and organic Rankine cycles with two feedwater heaters using artificial bees colony and artificial neural network. Energy, 36, 5728-5740.

Reichl, J., \& Kollmann, A. (2011). The baseline in bottom-up energy efficiency and saving calculations - a concept for its formalization and a discussion of relevant options. Applied Energy, 88, 422-431.
Romero, C. E., \& Shan, J. (2005). Development of an artificial neural network-based software for prediction of power plant canal water discharge temperature. Expert Systems with Applications, 29, 831-838.

Rumelhart, D. E., Hinton, G. E., \& Williams, R. J. (1986). Learning internal representations by error propagation. Parallel distributed processing: explorations in the microstructure of cognition, Vol. 1(1), (pp. 318-362). Cambridge, MA: MIT Press.

Rusinowski, H., \& Stanek, W. (2007). Neural modelling of steam boilers. Energy Conversion and Management, 48, 2802-2809.

Satish, S., \& Setty, Y. P. (2005). Modeling of a continuous fluidized bed dryer using artificial neural networks. International Communications in Heat and Mass Transfer, 32, 539-547.

Simani, S., \& Fantuzzi, C. (2000). Fault diagnosis in power plant using neural networks. Information Sciences, 127, 125-136.

Sisworahardjo, N. S., El-Sharkh, M. Y., \& Alamb, M. S. (2008). Neural network controller for microturbine power plants. Electric Power Systems Research, 78, 1378-1384.

Smrekar, J., Pandit, D., Fast, M., Assadi, M., \& De, S. (2010). Prediction of power output of a coal-fired power plant by artificial neural network. Neural Computing E' Applications, 19, 725-740.

Sözen, A., \& Akçayol, M. A. (2004). Modelling (using artificial neural-networks) the performance parameters of a solar-driven ejector-absorption cycle. Applied Energy, 79, 309-325.

Suresh, M. V. J. J., Reddy, K. S., \& Kolar, A. K. (2011). ANN-GA based optimization of a high ash coal-fired supercritical power plant. Applied Energy, 88, 4867-4873.

Tasdemir, S., Saritas, I., Ciniviz, M. \& Allahverdi, N. (2011). Artificial neural network and fuzzy expert system comparison for prediction of performance and emission parameters on a gasoline engine. Expert Systems with Applications, 38, 13912-13923.

Teruel, E., Cortes, C., Diez, L. I., \& Arauzo, I. (2005). Monitoring and prediction of fouling in coal-fired utility boilers using neural networks. Chemical Engineering Science, 60, 5035-5048.

Thermoflow Inc., (2013). 2 Willow Street, Suite 100, Southborough, MA 017451020, USA. <http://www.thermoflow.com>.

Tronci, S., Baratti, R., \& Servida, A. (2002). Monitoring pollutant emissions in a 4.8 MW power plant through neural network. Neurocomputing, 43, 3-15.

U.S. EPA State Clean Energy and Climate Program. (2009). Clean energy lead by example guide: Strategies, resources, and action steps for state programs, prepared by Joanna Pratt and Joe Donahue. Stratus Consulting Inc.

Vargas-Martínez, A., Minchala Avila, L. I., Zhang, Y., Garza-Castañón, L. E., \& Calle Ortiz, E. R. (2013). Model-based fault-tolerant control to guarantee the performance of a hybrid wind-diesel power system in a microgrid configuration. Procedia Computer Science, 19, 712-719.

Velázquez, D., González-Falcón, R., Pérez-Lombard, L., Gallego, L. M., Monedero, I., \& Biscarri, F. (2013). Development of an energy management system for a naphtha reforming plant: A data mining approach. Energy Conversion and Management, 67, 217-225.

Volponi, A. J., DePold, H., Ganguli, R., \& Daguang, C. (2003). The use of Kalman filter and neural network methodologies in gas turbine performance diagnostics: A comparative study. Journal of Engineering for Gas Turbines and Power, 125, 917-924.

Yap, W. K., \& Karri, V. (2013). Comparative analysis of artificial neural networks and dynamic models as virtual sensors. Applied Soft Computing, 13, 181-188.

Yeh, W.-C., Yeh, Y.-M., Chang, P.-C., Ke, Y.-C., \& Chung, V. (2014). Forecasting wind power in the Mai Liao wind farm based on the multi-layer perceptron artificial neural network model with improved simplified swarm optimization. International Journal of Electrical Power and Energy Systems, 55, 741-748. 